\title{
Clinical risk profile associated with SARS-CoV-2 infection and complications in the emergency area of a pediatric COVID-19 center
}

\author{
Víctor Olivar-López ${ }^{1}$, Ana Leyva-Barrera, Briceida López-Martínez², Israel Parra-Ortega³, and \\ Horacio Márquez-González * \\ ${ }^{1}$ Departamento de Urgencias; ${ }^{2}$ Subdirección de Servicios Auxiliares y Diagnóstico; ${ }^{3}$ Departamento de Laboratorio Clínico; ${ }^{4}$ Departamento de \\ Investigación Clínica. Hospital Infantil de México Federico Gómez, Mexico City, Mexico
}

\begin{abstract}
Background: In February 2020, the disease caused by the novel coronavirus (SARS-CoV-2), was classified as a pandemic. In the pediatric population, coronavirus disease (COVID)-19 has a reported mortality of less than 6\% in complicated cases; however, the clinical characteristics and severity are not the same as those presented in the adult population. This study aimed to describe the clinical manifestations of patients younger than 18 years old and their association with the confirmation of the test and outcomes. Methods: We conducted an analytical cross-sectional study of symptoms suggestive for SARS-CoV-2 infection. All subjects with a confirmatory test for SARS-CoV-2 were included. Initial symptoms, history of influenza vaccination, and previous contact were documented, and mortality and the requirement for assisted mechanical ventilation were identified. The proportions of the variables were compared with the $\chi^{2}$ test. The odds ratio for a positive test and the requirement of intubation was calculated. Results: Of a total of 510 subjects, 76 (15\%) were positive for SARS-CoV-2. The associated symptoms were chest pain, sudden onset of symptoms, and general malaise. The variable most associated with contagion was the exposure to a relative with a confirmed diagnosis of COVID-19. Infants and subjects without the influenza vaccine showed an increased risk for respiratory complications. Conclusions: The frequency of positivity in the test was $15 \%$ (infants and adolescents represented $64 \%$ of the confirmed cases), and the associated factors identified were contact with a confirmed case, sudden onset of symptoms, and chest pain.
\end{abstract}

Key words: Coronavirus disease-19. Pediatric. Emergency medical care. Endotracheal intubation. Mexico.

\section{Perfil clínico de riesgo asociado a infección y complicaciones por SARS-CoV-2 en el área de urgencias de un centro pediátrico COVID-19}

\section{Resumen}

Introducción: En 2019 se reportaron los primeros casos de SARS-CoV-2 (coronavirus tipo 2 del síndrome respiratorio agudo grave), causante de la COVID-19, que alcanzó el grado de pandemia en febrero de 2020. La presentación en la etapa pediátrica reporta una mortalidad menor del $6 \%$ en los casos complicados; sin embargo, las características clínicas y su gravedad no son iguales que en la población adulta. El objetivo de este estudio fue describir las manifestaciones clínicas

\section{Correspondence:}

*Horacio Márquez-González

E-mail: horaciohimfg@gmail.com

(http://creativecommons.org/licenses/by-nc-nd/4.0/)
Available online: 10-09-2020 Bol Med Hosp Infant Mex. 2020;77(5):221-227 www.bmhim.com 
de los pacientes menores de 18 años y su asociación con la confirmación de la prueba, la intubación endotraqueal y la muerte. Métodos: Estudio transversal analítico por cuadro sugestivo de infección por SARS-CoV-2. Se incluyeron sujetos positivos para SARS-CoV-2. Se documentaron los síntomas iniciales, los antecedentes de vacunación contra la influenza y Ios contactos previos, y se identificaron los desenlaces de mortalidad y requerimiento de ventilación mecánica asistida. Se compararon las proporciones de las variables con la prueba $\chi^{2}$ y se calculó la razón de momios para la presencia de una prueba positiva y requerir intubación. Resultados: De un total de 510 sujetos, 76 (15\%) fueron positivos para SARS-CoV-2. Los síntomas asociados fueron dolor precordial, inicio súbito y malestar general. La variable asociada con mayor frecuencia el contagio fue la exposición a un familiar con COVID-19 confirmada. Los sujetos sin vacuna de la influenza presentaron un riesgo mayor de complicaciones respiratorias. Conclusiones: La frecuencia de positividad en la prueba fue del $15 \%$. Se identificaron como factores asociados a prueba positiva el contacto con un caso confirmado de COVID-19, el inicio súbito de los sintomas y el dolor precordial.

Palabras clave: COVID-19. Pediatría. Servicios de urgencias médicas. Intubación endotraqueal. México.

\section{Introduction}

In December 2019, several cases of pneumonia of unknown origin emerged in Wuhan, Hubei Province, China. Most of the patients reported exposure to the Wholesale Seafood Market in Huanan, which sold live animal species ${ }^{1}$. On January 30, 2020, the World Health Organization (WHO) warned that the outbreak of a new coronavirus, called severe acute respiratory syndrome coronavirus 2 (SARS-CoV-2) (which causes coronavirus disease [COVID]-19 disease), was highly virulent and caused respiratory illness ${ }^{2}$. Most cases were reported from China and were exported to other countries, spreading the contagion and reaching pandemic proportions in February $2020^{3}$.

Coronaviruses get their name from the distinguishing viral particles (virions) that crown their surface. This family of viruses infects a wide range of vertebrates, especially mammals and birds, and is considered the leading cause of viral respiratory infections worldwide. The incubation period for SARS-CoV-2 extends to 14 days, with an average time of 4-5 days from exposure to the onset of symptoms ${ }^{4}$. Atypical presentations have been described in older adults; delay in the onset of fever and respiratory symptoms is sometimes observed in people with other comorbidities. Fever has been found in $89 \%$ of patients during their hospitalization, as well as headache, confusion, rhinorrhea, sore throat, hemoptysis, vomiting, and diarrhea (less common $<10 \%$ ). Several studies have reported that the signs and symptoms of COVID-19 in children are similar to those in adults but milder ${ }^{5}$. The clinical picture varies from a mild upper respiratory airway condition to severe pneumonia with sepsis. In infants with SARS-CoV-2 infection, fever, lethargy, rhinorrhea, cough, tachypnea, increased breathing effort, vomiting, diarrhea, and feeding intolerance or decreased intake have been detected, which may be confused with other pathologies, given the non-specificity of the symptoms ${ }^{5}$.

Because asymptomatic individuals are not routinely tested, the prevalence of asymptomatic infection and the detection of pre-symptomatic infection are not well known. Up to $13 \%$ of patients with positive reverse transcriptase-polymerase chain reaction (RT-PCR) tests were found to be asymptomatic. The exact degree of SARS-CoV-2 viral ribonucleic acid that confers transmission risk is not yet precise. The risk of transmission is thought to be higher when patients have symptoms since viral shedding is higher at the onset of symptoms and decreases over several days to weeks ${ }^{6}$.

Despite the global spread, the epidemiological and clinical patterns of COVID-19 remain unclear, particularly among children. The clinical manifestations of COVID-19 in children are generally reported to be less severe and less frequent than in adult patients ${ }^{3}$. In Mexico, the first documented case was in the last week of February, and the cessation of school and work activities for confinement purposes to prevent the spread was issued in March. In this phase (with a high spread of cases and during the Jornada Nacional de Sana Distancia program), the health system was modified, and the so-called COVID centers were created, which organized all their structure for the care of infected patients ${ }^{7}$. Therefore, the objective of this study was to describe the profile of patients under 18 years of age treated at a pediatric COVID center and its association with test confirmation, endotracheal intubation, and death.

\section{Methods}

An analytical cross-sectional study was conducted in the emergency department of a COVID pediatric reference hospital in Mexico City from March to June 2020. 
Patients under 18 years of age who came for a consultation with a clinical picture compatible with SARSCoV-2 (fever, respiratory symptoms, or general malaise) and who underwent RT-PCR testing were included in the study. Those with unreported test results or samples referred to as insufficient or poorly taken were excluded from the study.

Patients were initially classified in a specific area where general data, primary symptoms, and comorbidities were registered and explored.

Recorded clinical data were fever $\left(>38^{\circ} \mathrm{C}\right.$ sustained for $1 \mathrm{~h}$ or $38.3^{\circ} \mathrm{C}$ at any time), cough, odynophagia, dyspnea, diarrhea, acute general malaise (in $<24 \mathrm{~h}$ ), rhinorrhea, polypnea (according to age), vomiting, conjunctivitis, and cyanosis. Moreover, in children $<2$ years of age, the presence of irritability was interrogated, and in children $>5$ years of age, the presence of headache, chest pain, myalgias, arthralgias, and abdominal pain was examined.

Based on the physical examination and vital signs, a severe condition was defined by the presence of rales, alterations in the state of consciousness, tachypnea, tachycardia, fever, and desaturation of $<90 \%$ (measured with pulse oximetry).

According to age, the patients were classified as infants ( $<2$ years), preschoolers (2.1-6 years), schoolchildren (6.1-12 years), and adolescents (over 12.1 years).

Samples were obtained by nasopharyngeal swab and analyzed in laboratories authorized by the Secretaría de Salud (Mexican Ministry of Health).

Pre-existing comorbidities were recorded in the following categories: cancer (any hemato-oncological neoplasm under treatment), neurological disorders (conditions with malformations, epilepsy or developmental disorders that result in intellectual disability), congenital heart diseases (repaired or non-repaired), autoimmune diseases (specifically systemic lupus erythematosus disease, juvenile, or rheumatoid arthritis), allergic (asthma, atopic dermatitis, and cow's milk protein allergy), intestinal surgery (intestinal atresia of any degree or pancreatitis), infectious (specifically: acquired immunodeficiency virus), syndromic (spectrum of diseases conditioned by chromosomal alterations of Mendelian transmission, trisomies, or chromosomal deletions), renal (chronic kidney disease from any cause or a kidney transplant), pulmonary (pulmonary hypertension of WHO Groups III, IV, and V; cystic fibrosis and lung malformations), endocrinology (hypothyroidism, diabetes mellitus, and panhypopituitarism), and obesity.
The outcomes recorded were home surveillance, hospitalization (including intensive care areas), need for assisted mechanical ventilation, and death.

\section{Statistical analysis}

Qualitative variables were expressed in frequencies and percentages, age in median, and interquartile ranges. A comparative analysis was performed between positive and negative SARS-CoV-2 subjects with a $\chi^{2}$ test. Furthermore, the proportion of symptoms presentation according to pediatric stages was compared with the linear $\chi^{2}$ test. The risk was estimated with bivariate odds ratio (OR) analysis according to the symptoms associated with a positive test and required ventilatory mechanical support. $p<0.05$ was considered statistically significant. The statistical program used was SPSS version 20 for MAC from IBM®.

\section{Results}

During the study time frame, 540 tests were taken (30 were discarded due to poor technique or insufficient sample), and 510 patients were included, with a median age of 5 (1.3-11) years; 270 (53\%) were male. According to age groups, the distribution was as follows: infants, 148 (29\%); preschoolers, 134 (26.7\%); schoolchildren, $104(20.4 \%)$, and adolescents, 122 (24\%). Infants and adolescents were the most frequently infected groups (32.5\% for both). When comparing subjects with and with no SARS-CoV-2 infection, the only variable that showed statistical differences was the history of contact with a positive case $(27.6 \%$ vs. $57.9 \%)$. The remaining variables are shown in table 1.

A comparative analysis between subjects with and with no SARS-CoV-2 infection and their comorbidities was performed; no statistically significant differences were found (Table 2).

The difference in the presentation of symptoms between subjects with and with no the infection showed that the variables with $p<0.05$ value were chest pain ( $6 \%$ vs. $14 \%$ ), general malaise ( 33 vs. $44 \%$ ), and sudden onset of symptoms (63\% vs. $75 \%$ ). These three variables also showed statistically significant $O R$ values. When comparing the presentation of symptoms between age groups in patients with SARS-CoV-2 infection, those that presented differences were dyspnea, irritability, shivers, myalgias, arthralgias, general malaise, and abdominal pain (Table 3).

A total of 11 patients (19.3\%) required assisted mechanical ventilation. Bivariate analysis showed that the 
Bol Med Hosp Infant Mex. 2020;77(5)

Table 1. Characteristics of pediatric patients with and with no SARS-CoV-2 infection

\begin{tabular}{|c|c|c|c|c|c|c|}
\hline & \multirow{3}{*}{$\begin{array}{c}\text { Total } \\
510\end{array}$} & \multirow{2}{*}{\multicolumn{2}{|c|}{$\frac{\text { No SARS-CoV-2 }}{431}$}} & \multirow{2}{*}{\multicolumn{2}{|c|}{$\begin{array}{c}\text { SARS-CoV-2 } \\
79\end{array}$}} & \multirow[t]{3}{*}{$\mathbf{p}^{*}$} \\
\hline & & & & & & \\
\hline & & Frequency & $\%$ & Frequency & $\%$ & \\
\hline Age (years) & $5(1.3-11)$ & 5 & $1.4-11$ & 4.9 & $1.2-13$ & 0.9 \\
\hline $\begin{array}{l}\text { Gender } \\
\text { Male } \\
\text { Female }\end{array}$ & $\begin{array}{l}270 \\
240\end{array}$ & $\begin{array}{l}223 \\
208\end{array}$ & $\begin{array}{l}51.7 \\
48.3\end{array}$ & $\begin{array}{l}47 \\
32\end{array}$ & $\begin{array}{l}59.5 \\
40.5\end{array}$ & 0.2 \\
\hline $\begin{array}{l}\text { Age group } \\
<2 \text { years } \\
\text { Preschoolers } \\
\text { Schoolchildren } \\
\text { Adolescents }\end{array}$ & $\begin{array}{l}148 \\
134 \\
104 \\
122\end{array}$ & $\begin{array}{c}123 \\
118 \\
93 \\
97\end{array}$ & $\begin{array}{l}28.5 \\
27.4 \\
21.6 \\
22.5\end{array}$ & $\begin{array}{l}25 \\
16 \\
11 \\
25\end{array}$ & $\begin{array}{l}32.5 \\
20.8 \\
14.3 \\
32.5\end{array}$ & 0.1 \\
\hline $\begin{array}{l}\text { Origin } \\
\text { Mexico City } \\
\text { State of Mexico } \\
\text { Other }\end{array}$ & $\begin{array}{c}195 \\
218 \\
97\end{array}$ & $\begin{array}{l}164 \\
185 \\
82\end{array}$ & $\begin{array}{l}38.1 \\
42.9 \\
19.0\end{array}$ & $\begin{array}{l}31 \\
33 \\
15\end{array}$ & $\begin{array}{l}39.2 \\
41.8 \\
19.0\end{array}$ & 0.1 \\
\hline Influenza vaccine & 119 & 96 & 23.3 & 23 & 29.5 & 0.6 \\
\hline Contact & 160 & 116 & 27.6 & 44 & 57.9 & 0.001 \\
\hline Intubated & 44 & 33 & 12.3 & 11 & 19.3 & 0.5 \\
\hline Comorbidities & 231 & 185 & 42.9 & 46 & 58.2 & 0.06 \\
\hline
\end{tabular}

SARS-CoV-2: severe acute respiratory syndrome coronavirus 2

${ }^{*}$ Mann-Whitney's U-test; linear $\chi^{2}$ test.

Table 2. Comparison of comorbidities between patients with and with no SARS-CoV-2 infection

\begin{tabular}{|c|c|c|c|c|c|c|}
\hline \multirow[t]{3}{*}{ Type of comorbidity } & \multicolumn{2}{|c|}{ Total } & \multicolumn{2}{|c|}{ No SARS-CoV-2 } & \multicolumn{2}{|c|}{ SARS-CoV-2 } \\
\hline & \multicolumn{2}{|c|}{$n=231$} & \multicolumn{2}{|c|}{$\mathrm{n}=\mathbf{1 8 5}$} & \multicolumn{2}{|c|}{$n=46$} \\
\hline & Frequency & $\%$ & Frequency & $\%$ & Frequency & $\%$ \\
\hline Cancer & 77 & 33.3 & 60 & 32.4 & 17 & 37 \\
\hline Neurological & 23 & 10 & 19 & 10.3 & 4 & 8.7 \\
\hline Congenital heart disease & 32 & 13.9 & 27 & 14.6 & 5 & 10.9 \\
\hline Autoimmune & 12 & 5.2 & 11 & 5.9 & 1 & 2.2 \\
\hline Allergic & 15 & 6.5 & 13 & 7 & 2 & 4.3 \\
\hline Surgical & 12 & 5.2 & 9 & 4.9 & 3 & 6.5 \\
\hline Infectious & 8 & 3.5 & 6 & 3.2 & 2 & 4.3 \\
\hline Syndromic & 11 & 4.8 & 9 & 4.9 & 2 & 4.3 \\
\hline Kidney & 15 & 6.5 & 11 & 5.9 & 4 & 8.7 \\
\hline Pulmonary & 11 & 4.8 & 10 & 5.4 & 1 & 2.2 \\
\hline Endocrinological & 6 & 2.6 & 5 & 2.7 & 1 & 2.2 \\
\hline Obesity & 9 & 3.9 & 5 & 2.7 & 4 & 8.7 \\
\hline
\end{tabular}

SARS-CoV-2: severe acute respiratory syndrome coronavirus 2.

$\chi^{2}$ test, no statistically significant differences were found. 
Table 3. Differences in the presentation of symptoms in patients with and with no positive test for SARS-CoV-2

\begin{tabular}{|c|c|c|c|c|c|c|c|c|c|c|c|c|c|c|c|c|}
\hline \multirow[t]{3}{*}{ Symptoms } & \multirow[t]{3}{*}{ Total } & \multirow{2}{*}{\multicolumn{2}{|c|}{$\begin{array}{l}\text { No } \\
\text { SARS- } \\
\text { CoV-2 }\end{array}$}} & \multirow{2}{*}{\multicolumn{2}{|c|}{$\begin{array}{l}\text { SARS- } \\
\text { CoV-2 }\end{array}$}} & \multirow[t]{3}{*}{$\mathbf{p}^{*}$} & \multirow[t]{3}{*}{ OR (95\% CI) } & \multirow{2}{*}{\multicolumn{2}{|c|}{$\begin{array}{c}\text { Neonates } \\
n=25\end{array}$}} & \multirow{2}{*}{\multicolumn{2}{|c|}{$\begin{array}{c}\text { Preschoolers } \\
n=16\end{array}$}} & \multirow{2}{*}{\multicolumn{2}{|c|}{$\begin{array}{c}\text { Schoolchildren } \\
n=11\end{array}$}} & \multirow{2}{*}{\multicolumn{2}{|c|}{$\begin{array}{c}\text { Adolescents } \\
n=25\end{array}$}} & \multirow[t]{3}{*}{$\mathbf{p}^{* *}$} \\
\hline & & & & & & & & & & & & & & & & \\
\hline & & n & $\%$ & n & $\%$ & & & n & $\%$ & n & $\%$ & n & $\%$ & $n$ & $\%$ & \\
\hline Fever & 313 & 266 & 62 & 47 & 60 & 0.6 & $0.9(0.5-1.4)$ & 12 & 48 & 12 & 75 & 7 & 64 & 16 & 64 & 0.2 \\
\hline Cough & 210 & 171 & 40 & 39 & 49 & 0.1 & $1.4(0.9-2.3)$ & 13 & 52 & 6 & 38 & 8 & 73 & 12 & 48 & 0.3 \\
\hline Odynophagia & 96 & 82 & 21 & 14 & 19 & 0.6 & $0.8(0.4-1.5)$ & \multicolumn{2}{|c|}{ NA } & 4 & 25 & 1 & 9 & 9 & 36 & 0.3 \\
\hline Dyspnea & 145 & 117 & 28 & 28 & 35 & 0.1 & $1.4(0.8-2.4)$ & 7 & 28 & 2 & 13 & 7 & 64 & 12 & 48 & 0.008 \\
\hline Irritability & 180 & 154 & 36 & 26 & 33 & 0.6 & $0.8(0.5-1.4)$ & 13 & 52 & 7 & 44 & 1 & 9 & 5 & 20 & 0.01 \\
\hline Diarrhea & 100 & 83 & 19 & 17 & 22 & 0.6 & $1.1(0.6-2)$ & 4 & 16 & 5 & 31 & 2 & 18 & 6 & 24 & 0.07 \\
\hline Chest pain & 32 & 22 & 6 & 10 & 14 & 0.01 & $2.6(1.2-6)$ & \multicolumn{2}{|c|}{ NA } & 1 & 6 & 1 & 9 & 8 & 32 & 0.4 \\
\hline Shivers & 113 & 93 & 23 & 20 & 26 & 0.6 & $1.1(0.6-2)$ & 1 & 4 & 7 & 44 & 4 & 36 & 8 & 32 & 0.004 \\
\hline Headache & 108 & 88 & 22 & 20 & 26 & 0.3 & $1.2(0.7-2.2)$ & \multicolumn{2}{|c|}{ NA } & 5 & 31 & 5 & 45 & 10 & 40 & 0.01 \\
\hline Myalgia & 69 & 54 & 14 & 15 & 20 & 0.1 & $1.5(0.8-2.8)$ & \multicolumn{2}{|c|}{ NA } & 3 & 19 & 3 & 27 & 9 & 36 & 0.01 \\
\hline Arthralgia & 55 & 44 & 12 & 11 & 15 & 0.4 & $1.3(0.6-2.7)$ & \multicolumn{2}{|c|}{ NA } & 1 & 6 & 2 & 18 & 8 & 32 & 0.01 \\
\hline General malaise & 164 & 130 & 33 & 34 & 44 & 0.04 & $1.6(1.2-2.6)$ & 7 & 28 & 6 & 38 & 7 & 64 & 14 & 56 & 0.01 \\
\hline Rhinorrhea & 124 & 106 & 26 & 18 & 23 & 0.6 & $0.8(0.4-1.5)$ & 4 & 16 & 4 & 25 & 3 & 27 & 7 & 28 & 0.4 \\
\hline Polypnea & 138 & 115 & 29 & 23 & 30 & 0.8 & $1(0.2-1.8)$ & 11 & 44 & 2 & 13 & 4 & 36 & 6 & 24 & 0.2 \\
\hline Vomiting & 94 & 75 & 19 & 19 & 24 & 0.1 & $1.4(0.7-2.5)$ & 5 & 20 & 3 & 19 & 5 & 45 & 6 & 24 & 0.2 \\
\hline Abdominal pain & 108 & 91 & 24 & 17 & 22 & 0.7 & $0.9(0.5-1.6)$ & \multicolumn{2}{|c|}{ NA } & 7 & 44 & 5 & 45 & 5 & 20 & 0.002 \\
\hline Conjunctivitis & 45 & 35 & 9 & 10 & 13 & 0.9 & $1.5(0.7-3.2)$ & 3 & 12 & 2 & 13 & 2 & 18 & 3 & 12 & 0.8 \\
\hline Cyanosis & 45 & 40 & 10 & 5 & 6 & 0.3 & $0.6(0.2-1.6)$ & 2 & 8 & 1 & 6 & 2 & 18 & 0 & 0 & 0.1 \\
\hline Sudden onset & 317 & 258 & 63 & 59 & 75 & 0.05 & $2.5(1.5-4)$ & 17 & 68 & 14 & 88 & 10 & 91 & 17 & 68 & 0.1 \\
\hline
\end{tabular}

Cl: confidence interval; OR: odds ratio; SARS-CoV-2: severe acute respiratory syndrome coronavirus 2.

${ }^{*} \chi^{2}$ test; ${ }^{* *}$ linear $\chi^{2}$ test.

variables associated with this outcome were age $<2$ years, history of not having influenza vaccination, sudden onset of symptoms, and hemato-oncologic pathology. OR values are shown in figure 1.

Only one patient from the SARS-CoV-2 group died. This patient arrived at the emergency department in asystole and did not respond to resuscitation maneuvers.

\section{Discussion}

In this pediatric series of patients treated for respiratory symptoms in the context of the SARS-CoV-2 pandemic, we were able to describe the clinical characteristics of 510 children who were treated in an emergency department.

The frequency of disease by the confirmatory test was $15 \%$ (i.e., 1.5 out of 10 patients evaluated). This proportion is compatible with that reported in other pediatric series, in which the frequency of diagnosis ranged between 10 and $15 \%{ }^{8}$. This pattern could be explained by the fact that the preventive strategy of most countries has been to confine this population group due to the limited possibility of adherence to standard protection measures ${ }^{9}$.

The population in this study demonstrated a bimodal diagnosis pattern: $64 \%$ of cases were equally distributed among children $<2$ years and adolescents. The reason for this distribution is yet unclear. However, the pathophysiological justification is by the mechanism associated with the angiotensin II inhibitory enzyme ${ }^{10}$ and the thymus-dependent immune response ${ }^{11}$.

In this case, the sudden onset of symptoms, as well as general malaise, and chest pain were found to be 


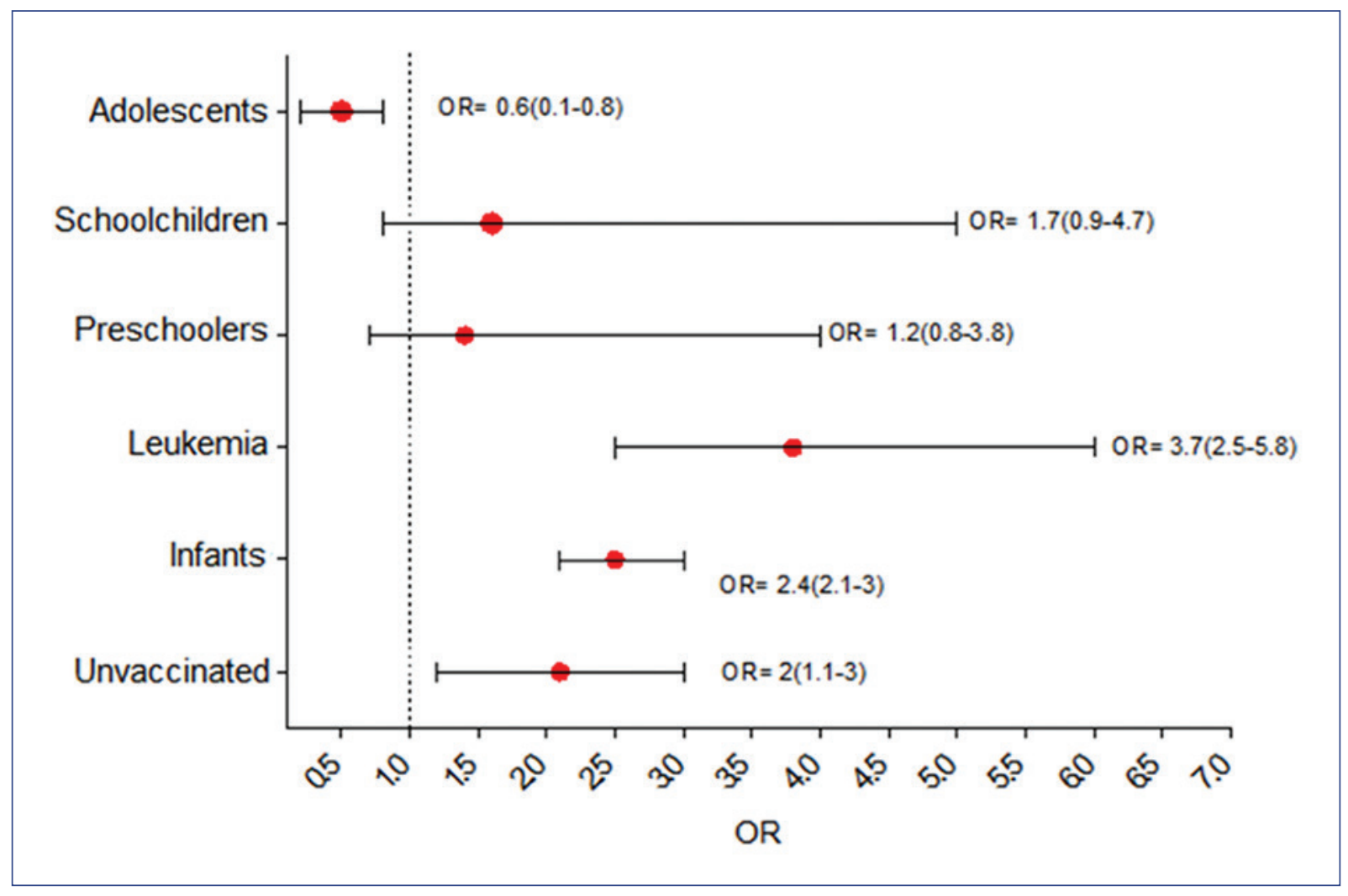

Figure 1. Calculated odds ratio for children infected with severe acute respiratory syndrome type 2 coronavirus requiring mechanical ventilatory support. Unvaccinated refers to no seasonal influenza vaccine.

the symptoms most associated with a positive test. These results differ from those expected in adults, as shown by a meta-analysis conducted by RodriguezMorales et al., who reported, after reviewing 19 articles, that fever, cough, and dyspnea were the most representative symptoms in the adult population and were associated with a worse outcome ${ }^{12}$. This discrepancy was present because the frequency of respiratory complications and the need for mechanical assistance were not different from that of subjects with no SARS-CoV-2 infection. Therefore, it represented $11 \%$ in this series of patients.

The contact of children with a confirmed case of COVID-19 was the variable most associated with the development of the disease and is the leading cause of contagion within families, with primary caregivers being the ones initially affected ${ }^{13}$. Vertical infection through the birth canal or transplacental route has been reported ${ }^{14}$. However, in this study, these modes of transmission could not be assessed, because the infants were not attended in our hospital emergency department but were referred by other centers directly to the neonatal intensive care unit.
Another condition that should be discussed is the history of influenza vaccination and its risk association with the need for intubation. Although only $23 \%$ of all children were vaccinated, the subgroup of intubated children showed an OR of 2.5. Coinfection of SARS-CoV-2 with other respiratory viruses or vaccine-preventable bacterial cases of pneumonia has been described since the beginning of the pandemic $^{15}$. This observation is consistent with our results since the first cases of COVID-19 in Mexico, and the first week of Phase III developed during the expected season of respiratory infections by influenza. Moreover, some of the cases detected in March were also analyzed for other respiratory viruses. An association of SARS-CoV-2 and influenza was found in $13 \%$ of these cases.

COVID-19-related mortality in our emergency department was $<2 \%$, accordingly with reports by multicenter studies, such as Critical Coronavirus and Kids Epidemiology, conducted in 17 critical care centers in the United States, where mortality from SARS-CoV-2 was $6 \%{ }^{16}$. 
Tiago et al. recently published a meta-analysis that included 28 studies (1124 cases) of SARSCoV-2 infection, which reported moderate symptoms in $46 \%$ of patients; mechanical ventilation was required in 10 cases. Concerning clinical data, the most frequent sign was fever $(47 \%)$, and the most prevalent symptom was cough $(41.5 \%)$. In this regard, it should be noted that the articles included were only cases with confirmed patients. In that population, the proportion of subjects with endotracheal intubation was higher because of the coexistence with other pathologies ${ }^{17}$.

Our results show that the conditions of our hospital represent the scenario of the pandemic in the pediatric population in Mexico at the first contact level. It also delimits a population at risk, with specific symptoms and relevant background. Therefore, pediatricians can make a better decision when it comes to prioritizing resources. Consequently, infants and adolescents with sudden onset of symptoms (chest pain for children who can report it) and a history of contact with a confirmed COVID-19 patient may be the primary factors to be screened with testing. Furthermore, positive patients with no history of influenza vaccine are at higher risk of severe complications. Fever is a common sign in patients with and with no confirmed infection, which determines one of the main reasons for consultation. However, it is not possible to discriminate between them.

The present results are descriptive and exploratory of the general scenario. Laboratory studies, short- and long-term follow-up, and measurement of potentially confounding variables are necessary to achieve an accurate prognostic study without misclassification, memory, and inclusion biases. Furthermore, the extent of the treatments applied should be assessed.

In pediatric patients with SARS-CoV-2 infection suspicion, the frequency of positive test results was $15 \%$ (infants and adolescents represented $64 \%$ of confirmed cases). The contact with a confirmed case, sudden onset of symptoms, and chest pain were factors associated with a positive test result.

\section{Ethical disclosures}

Protection of human and animal subjects. The authors declare that no experiments were performed on humans or animals for this study.
Confidentiality of data. The authors declare that they have followed the protocols of their work center on the publication of patient data.

Right to privacy and informed consent. The authors have obtained the written informed consent of the patients or subjects mentioned in the article. The corresponding author has this document.

\section{Conflicts of interest}

The authors declare no conflicts of interest.

\section{Funding}

None.

\section{References}

1. Giwa AL, Desai A, Duca A. Novel 2019 coronavirus SARS-CoV-2 (COVID-19): an overview for emergency clinicians. Pediatr Emerg Med Pract. 2020;17:1-24.

2. World Health Organization. Critical Preparedness, Readiness, and Response Actions for COVID-19. Interim Guidance. Ginebra; 2020. Available from: https://www.who.int/publications/i/item/critical-preparedness-readiness-and-response-actions-for-covid-19.

3. Dong $Y$, Mo X, Hu Y, Qi X, Jiang F, Jiang Z, et al. Epidemiology of COVID-19 among children in China. Pediatrics. 2020;145:e20200702.

4. Wu Z, McGoogan JM. Characteristics of and important lessons from the coronavirus disease 2019 (COVID-19) outbreak in China: summary of a report of 72314 cases from the Chinese center for disease control and prevention. JAMA. 2020;323(13):1239-42. doi:10.1001/jama.2020.2648.

5. Chen $\mathrm{D}$, Yang $\mathrm{H}$, Cao $\mathrm{Y}$, Cheng $\mathrm{W}$, Duan $\mathrm{T}$, Fan $\mathrm{C}$, et al. Expert consensus for managing pregnant women and neonates born to mothers with suspected or confirmed novel coronavirus (COVID-19) infection. Int J Gynaecol Obstet. 2020;149:130-6.

6. Carlotti A, Carvalho WB, Johnston C, Rodriguez IS, Delgado AF. COVID-19 Diagnostic and management protocol for pediatric patients. Clinics (Sao Paulo). 2020;75:e1894.

7. Secretaría de Salud. Coronavirus. Datos Abiertos. Mexico; 2020. Available from: https://www.gob.mx/salud/documentos/datos-abiertos-152127. [Last accessed on 2020 Jun 20].

8. Lu X, Zhang L, Du H, Zhang J, Li YY, Qu J, et al. SARS-CoV-2 infection in children. N Engl J Med. 2020;382:1663-5.

9. Cao Q, Chen YC, Chen CL, Chiu CH. SARS-CoV-2 infection in children: transmission dynamics and clinical characteristics. J Formos Med Assoc. 2020;119:670-3

10. Li Y, Zhou W, Yang L, You R. Physiological and pathological regulation of ACE2, the SARS-CoV-2 receptor. Pharmacol Res. 2020:157:104833.

11. Rehman S, Majeed T, Ansari MA, Ali U, Sabit H, Al-Suhaimi EA. Current scenario of COVID-19 in the pediatric age group and physiology of immune and thymus response. Saudi J Biol Sci. 2020. doi: 10.1016/j. sjbs.2020.05.024 [ahead of print].

12. Rodriguez-Morales AJ, Cardona-Ospina JA, Gutierrez-Ocampo E, Villamizar-Pena R, Holguin-Rivera Y, Escalera-Antezana JP, et al. Clinical, laboratory and imaging features of COVID-19: a systematic review and meta-analysis. Travel Med Infect Dis. 2020;34:101623.

13. Mao LJ, Xu J, Xu ZH, Xia XP, Li B, He JG, et al. A child with household transmitted COVID-19. BMC Infect Dis. 2020;20:329.

14. Zimmermann $P$, Curtis N. COVID-19 in children, pregnancy and neonates: a review of epidemiologic and clinical features. Pediatr Infect Dis $\mathrm{J}$. 2020;39:469-77.

15. Wu D, Lu J, Ma X, Liu Q, Wang D, Gu Y, et al. Coinfection of influenza virus and severe acute respiratory syndrome coronavirus 2 (SARSCOV-2). Pediatr Infect Dis J. 2020;39:e79.

16. Gonzalez-Dambrauskas $S$, Vasquez-Hoyos $P$, Camporesi A, Diaz-Rubio F, Pineres-Olave BE, Fernandez-Sarmiento J, et al. Pediatric critical care and COVID-19. Pediatrics. 2020;146(3):e20201766.

17. de Souza TH, Nadal JA, Nogueira RJ, Pereira RM, Brandao MB. Clinical manifestations of children with COVID-19: a systematic review. Pediatr Pulmonol. 2020;55:1892-9. 